OPEN ACCESS

Edited by:

Silvina Perez-Martinez,

CONICET Centro de Estudios

Farmacológicos y Botánicos

(CEFYBO), Argentina

Reviewed by:

Elizabeth Breininger,

Consejo Nacional de Investigaciones Científicas y Técnicas (CONICET),

Argentina

Tzongshi Lu,

Brigham and Women's Hospital and Harvard Medical School,

United States

*Correspondence:

Marc Yeste

marc.yeste@udg.edu

Isabel Barranco

isabel.barranco@unibo.it

tThese authors have contributed equally to this work and share first

authorship

FThese authors have contributed equally to this work and share senior authorship

Specialty section:

This article was submitted to

Cell Growth and Division,

a section of the journal

Frontiers in Cell and Developmental

Biology

Received: 20 March 2021

Accepted: 18 May 2021

Published: 08 June 2021

Citation:

Mateo-Otero Y, Viñolas-Vergés E,

Llavanera M, Ribas-Maynou J,

Roca J, Yeste $M$ and Barranco I (2021) Aldose Reductase B1 in Pig

Seminal Plasma: Identification, Localization in Reproductive Tissues, and Relationship With Quality and Sperm Preservation. Front. Cell Dev. Biol. 9:683199. doi: 10.3389/fcell.2021.683199

\section{Aldose Reductase B1 in Pig Seminal Plasma: Identification, Localization in Reproductive Tissues, and Relationship With Quality and Sperm Preservation}

\author{
Yentel Mateo-Otero',2t, Estel Viñolas-Vergés ${ }^{1,2 t}$, Marc Llavanera', \\ Jordi Ribas-Maynou ${ }^{1,2}$, Jordi Roca ${ }^{3}$, Marc Yeste ${ }^{1,2 * \neq}$ and Isabel Barranco ${ }^{* \neq}$ \\ 'Biotechnology of Animal and Human Reproduction (TechnoSperm), Institute of Food and Agricultural Technology, University \\ of Girona, Girona, Spain, ${ }^{2}$ Unit of Cell Biology, Department of Biology, Faculty of Sciences, University of Girona, Girona, \\ Spain, ${ }^{3}$ Department of Medicine and Animal Surgery, Faculty of Veterinary Medicine, University of Murcia, Murcia, Spain, \\ ${ }^{4}$ Department of Veterinary Medical Sciences, University of Bologna, Bologna, Italy
}

Aldose reductase B1 (AKR1B1), a NADPH-dependent enzyme that belongs to the aldo-keto reductase protein superfamily, has been reported to be involved in both male and female reproductive physiology. The objectives of this study were: (1) to evaluate the concentration of SP-AKR1B1 in pig ejaculate fractions; (2) to describe the immunohistochemical localization of AKR1B1 alongside the boar genital tract; (3) to evaluate the relationship between SP-AKR1B1 and sperm quality/functionality parameters. Ejaculates from seven boars (one ejaculate per boar) were collected in separate portions [the first $10 \mathrm{~mL}$ of the sperm rich fraction (SRF-P1), the rest of the SRF (SRF-P2), and the post-SRF (PSRF)], and the concentration of SP-AKR1B1 was assessed using an enzyme-linked immunosorbent assay (ELISA). Immunohistochemistry and immunoblotting targeting was conducted in the reproductive tissues of these boars. Additionally, the entire ejaculates of 14 boars (one ejaculate per boar) were collected and split into three separate aliquots for: (i) SP-AKR1B1 quantification; (ii) assessment of sperm concentration and morphology; and (iii) evaluation of sperm quality and functionality parameters upon ejaculate collection $(\mathrm{O} \mathrm{h})$ and after $72 \mathrm{~h}$ of liquid storage at $17^{\circ} \mathrm{C}$. Concentration of AKR1B1 in the SP of SRF-P1 $(458.2 \pm 116.33 \mathrm{ng} / \mathrm{mL})$ was lower $(P<0.05)$ than that of SRFP2 (1105.0 $\pm 229.80 \mathrm{ng} / \mathrm{mL})$ and PSRF (1342.4 $\pm 260.18 \mathrm{ng} / \mathrm{mL})$. Monomeric and dimeric AKR1B1 forms were expressed alongside the reproductive tissues, except in the bulbourethral glands. No relationship between SP-AKR1B1 and sperm quality/functionality parameters was observed either at $0 \mathrm{~h}$ or after $72 \mathrm{~h}$ of storage at $17^{\circ} \mathrm{C}$. In conclusion, AKR1B1 is expressed in the reproductive organs of boars (except bulbourethral glands) and a higher concentration is found in the PSRF suggesting that seminal vesicles would be the main secretory source. However, this enzyme does not appear to be related to sperm quality/functionality or to the sperm ability to withstand liquid storage at $17^{\circ} \mathrm{C}$.

Keywords: aldose reductase B1, AKR1B1, seminal plasma, ejaculate fractions, sperm physiology, pig 


\section{INTRODUCTION}

Aldose reductase B1 (AKR1B1 or ALR2), a NADPH-dependent enzyme that belongs to the aldo-keto reductase protein superfamily (Bohren et al., 1989; Hyndman et al., 2003), has been reported to play an essential role in both male and female reproductive systems in humans (Bresson et al., 2011), cattle (Frenette et al., 2004; Girouard et al., 2009), rats (Kobayashi et al., 2002), sheep (Yang et al., 2019), and pigs (Steinhauser et al., 2016; Pérez-Patiño et al., 2018). This enzyme is known to be involved in the polyol pathway for fructose production, specifically in the conversion of glucose into sorbitol (Kobayashi et al., 2002). Interestingly, this pathway has been observed to occur during both epididymal sperm maturation in humans, cattle, and mice (Frenette et al., 2004, 2006; Jagoe et al., 2013) and conceptus peri-implantation period in pigs (Steinhauser et al., 2016). On the other hand, aldo-keto reductase enzymes have also been found to be implicated in catalyzing the reductive detoxification of carbonyl compounds within the genital tract of rat males (Kobayashi et al., 2002; Iuchi et al., 2004) and in prostaglandin $2 \alpha$ synthesis (PGF2 $\alpha$ ) in pigs and humans (Bresson et al., 2011; Seo et al., 2014). As previous studies reported that AKR1B1 is expressed in the endometrium of humans (Bresson et al., 2011) and pigs (Seo et al., 2014) and is involved in PGF2 $\alpha$ synthesis, it has been suggested that it could ultimately modulate conceptus implantation through regulation of endometrial gene expression in mammals (Kennedy et al., 2007; Seo et al., 2014). Finally, and reinforcing the belief that this protein plays a major role in reproduction, an in-depth proteomic analysis of pig seminal plasma (SP) revealed that AKR1B1 is positively related to in vivo fertility outcomes (Pérez-Patiño et al., 2018).

Seminal plasma, a complex fluid composed of secretions from the testis, epididymis, and male accessory sex glands, mixes with sperm upon ejaculation (Garner and Hafez, 2000). Although the classical roles attributed to SP are acting as a vehicle and serving as a nourishment media for sperm (Garner and Hafez, 2000), mounting evidence indicates that it plays a vital role for sperm function and modulates their fertilizing ability (Rodríguez-Martínez et al., 2011; Locatello et al., 2013). Moreover, SP also interacts with the female reproductive tract modulating the immune environment, a critical point required for successful pregnancy (O'Leary et al., 2004; Robertson, 2007; Schjenken and Robertson, 2014). For this reason, much research has focused on exploring the composition of SP, pointing to some SP-components as potential biomarkers of (in) fertility in several mammalian species (Novak et al., 2010; Milardi et al., 2013; Muhammad Aslam et al., 2014; Cazaux Velho et al., 2018; PérezPatiño et al., 2018; Leahy et al., 2019). In this regard, AKR1B1 in SP would be a clear candidate for a fertility biomarker due to its proven relationship with in vivo fertility (Pérez-Patiño et al., 2018). However, the mechanism through which SP-AKR1B1 could positively affect fertility in mammals remains unclear.

While the presence of AKR1B1 alongside the female reproductive system of several mammalian species has been extensively reported (Bresson et al., 2011; Seo et al., 2014; Steinhauser et al., 2016), the information about its role in the male genital tract and sperm physiology is scarce. Moreover, although AKR1B1 has been related to epididymal maturation in cattle (Frenette et al., 2004, 2006; Girouard et al., 2009) and mouse (Jagoe et al., 2013), the exact protein synthesis site in the male reproductive system is yet to be reported. In this sense, fractional emission of pig ejaculate offers a valuable opportunity to explore the contributions of specific male sex accessory glands to SP composition (Rodríguez-Martínez et al., 2009). Three fractions/portions can be objectively collected with clear differences in the SP source: (a) the first $10 \mathrm{~mL}$ of the so-called sperm rich fraction (SRF-P1), rich in sperm and with SP mainly originating from the epididymis; (b) the rest of SRF (SRF-P2), also rich in sperm and with SP mainly coming from the prostate (Rodríguez-Martínez et al., 2005, 2009), and, (c) the post-SRF (PSRF), poor in sperm and with SP mainly arising from the seminal vesicles (Einarsson, 1971; Rodríguez-Martínez et al., 2005, 2009; Saravia et al., 2009; Rodríguez-Martínez et al., 2011). Interestingly, the SP from these ejaculate portions has also been found to vary in terms of proteomic, metabolomic, and antioxidant capacity (Saravia et al., 2009; Rodríguez-Martínez et al., 2011; Barranco et al., 2015, 2016, 2017; Perez-Patiño et al., 2016; Mateo-Otero et al., 2020).

Considering the well-described relationship of SP-AKR1B1 with in vivo fertility outcomes in pigs (Pérez-Patiño et al., 2018) and the multiple key roles of AKR1B1 in reproductive physiology, the overall aim of the present study was to characterize the synthesis of SP-AKR1B1 alongside the male genital tract and to evaluate its involvement in sperm function. To this end, the specific objectives were: (1) to evaluate the concentration of SP-AKR1B1 in different pig ejaculate fractions; (2) to describe the immunohistochemical localization of AKR1B1 alongside the boar reproductive system; and (3) to evaluate the relationship between SP-AKR1B1 and sperm quality/functionality parameters in semen samples (sperm morphology, motility, viability, intracellular $\mathrm{H}_{2} \mathrm{O}_{2}$ production, acrosome integrity, and lipid disorder of plasma membrane). These sperm variables were assessed upon ejaculate collection and after $72 \mathrm{~h}$ of storage at $17^{\circ} \mathrm{C}$, as liquid storage for that period of time is the most common method for preserving pig semen prior to conducting AI (Kumaresan et al., 2009; Waberski et al., 2019).

\section{MATERIALS AND METHODS}

\section{Animals and Samples}

All samples were supplied by an Artificial Insemination (AI) Center of AIM Ibérica located in Calasparra (Murcia, Spain), which fulfills the Spanish (ES300130640127; August 2006) and European (ES13RS04P; July 2012) legislation on commercialization of pig semen and animal health and welfare. Samples (ejaculates and reproductive tissues) were obtained from healthy and sexually mature boars (aged 18-36 months) from different breeds and crossbreeds (Pietrain and Duroc). Boars were housed individually in a building with controlled conditions of air temperature $\left(15-25^{\circ} \mathrm{C}\right)$ and light ( $16 \mathrm{~h}$ per day), were fed with a commercial diet according to the nutritional requirements of adult boars (Chiba, 2009), and had ad libitum access to water. 
Sperm quality of each ejaculate used in the experiment was assessed immediately after ejaculation following the standard procedures used in the AI center. All samples fulfilled the standards of sperm number and quality thresholds for the preparation of semen doses used for AI, specifically, (i) more than $200 \times 10^{6}$ spermatozoa/mL, (ii) more than $70 \%$ of motile sperm, and (iii) more than $75 \%$ of morphologically normal sperm.

Boars were slaughtered in a commercial slaughterhouse (La Mata de los Olmos, Teruel, Spain) for genetic replacement reasons while they were still healthy and suitable as semen donors. Once slaughtered, tissue samples $(1 \mathrm{~cm} \times 1 \mathrm{~cm}$ and $1 \mathrm{~mm}$ thick) from testis, epididymis, and accessory sex glands were collected. Fresh (for immunoblotting analysis) or fixed (4\% phosphate-buffered formalin for immunohistochemical analysis) tissue samples were immediately frozen in liquid nitrogen.

\section{Experimental Design}

\section{Experiment 1: SP-AKR1B1 Concentration in Ejaculate Portions}

For the study of SP-AKR1B1 concentration in ejaculate fractions, the three fractions/portions (SRF-P1, SRF-P2, and PSRF) of seven ejaculates were collected separately, using the gloved hand method. The concentration of AKR1B1 in the SP of each portion was assessed using a porcine-specific enzyme-linked immunosorbent assay (ELISA), as described below.

\section{Experiment 2: Expression of AKR1B1 in Male Reproductive Organs}

Immunohistochemical and targeted immunoblotting analyses were conducted to find out which organs of the male reproductive system secreted AKR1B1. The samples, from three boars, came from medial testis; caput, corpus, and cauda segments of epididymis; and mid-areas of the prostate, seminal vesicles and bulbourethral glands.

\section{Experiment 3: Relationship Between SP-AKR1B1 and Sperm Quality/Functionality Parameters}

Entire ejaculates from 14 boars (one ejaculate per boar) were collected using a semi-automatic collection method (Collectis ${ }^{\circledR}$, IMV Technologies, L'Aigle, France) and split into three aliquots. The first aliquot was used for sperm concentration and morphology assessment. The second one was extended alike AI-dose $\left(30 \times 10^{6}\right.$ sperm $/ \mathrm{mL}$ in Biosem + extender, Magapor, Zaragoza, Spain) and used to evaluate sperm quality and functionality parameters (sperm motility and viability, intracellular $\mathrm{H}_{2} \mathrm{O}_{2}$ production by viable sperm, and acrosome damage and plasma membrane lipid disorder of viable sperm) after ejaculate collection $(0 \mathrm{~h})$ and after $72 \mathrm{~h}$ of liquid storage at $17^{\circ} \mathrm{C}$. Finally, the third aliquot was centrifuged to obtain SP. Next, SP samples were stored at $-80^{\circ} \mathrm{C}$ until the concentration of AKR1B1 was analyzed with an ELISA assay.

\section{Seminal Plasma Processing and Storage}

Immediately after ejaculate collection, semen samples were centrifuged twice at $1,500 \mathrm{~g}$ and room temperature for 10 min (Rotofix 32A, Hettich Centrifuges UK, Newport Pagnell,
Buckinghamshire, United Kingdom), following a previously described protocol (Perez-Patiño et al., 2016; Li et al., 2018; Barranco et al., 2019; Padilla et al., 2020). After the second centrifugation cycle, the supernatant was examined under a microscope (Eclipse E400, Nikon, Melville, NY, United States) to verify that it was sperm-free. Then, SP samples were split into cryotubes and stored at $-80^{\circ} \mathrm{C}$ (Ultra Low Freezer, Haier Inc., Qingdao, China) until analysis. Samples were thawed on ice prior to evaluation.

\section{Immunoblotting}

In order to lysate tissue samples, $50 \mathrm{mg}$ of each tissue was resuspended in $800 \mu \mathrm{L}$ of lysis buffer (xTractor ${ }^{\circledR}$ Buffer; Takara Bio, Mountain View, CA, United States) supplemented with 50 U DNase I (Takara Bio), 1\% protease inhibitor cocktail, and $700 \mathrm{mM}$ sodium orthovanadate. After incubation at $4^{\circ} \mathrm{C}$ for $10 \mathrm{~min}$, samples were disrupted mechanically four times using a TissueLyzer II (Qiagen, Hilden, Germany) set at 30 strokes/s for $5 \mathrm{~min}$ at $4^{\circ} \mathrm{C}$. Subsequently, centrifugation at $12,000 \mathrm{~g}$ and $4^{\circ} \mathrm{C}$ for $30 \mathrm{~min}$ was carried out in order to obtain the supernatants, which were finally collected and stored at $-80^{\circ} \mathrm{C}$. Finally, total protein was quantified in triplicate by a detergent compatible (DC) method (BioRad).

For each tissue sample, $10 \mu \mathrm{g}$ of total protein was diluted in $10 \mu \mathrm{L}$ of miliQ water. Then, $10 \mu \mathrm{L}$ of Laemmli reducing buffer $2 \times$ supplemented with $5 \%(\mathrm{v} / \mathrm{v}) \quad \beta$-mercaptoethanol (BioRad) was added to samples and boiled at $95^{\circ} \mathrm{C}$ for $5 \mathrm{~min}$. Following this, a total volume of $20 \mu \mathrm{L}$ per sample was loaded onto a polyacrylamide gradient $(8-16 \%)$ gel (Mini-PROTEAN ${ }^{\circledR}$ TGX Stain-FreeTM Precast Gels, Bio-Rad); electrophoresis ran at $120-150 \mathrm{~V}$ for approximately $1 \mathrm{~h}$. After electrophoresis, total protein content was visualized by UV exposition and acquisition using a G:BOX Chemi XL system (SynGene, Frederick, MD, United States). Afterward, proteins from the resulting gels were transferred onto polyvinylidene difluoride (PVDF) membranes using Trans-Blot ${ }^{\circledR}$ Turbo $^{\mathrm{TM}}$ (BioRad). Next, membranes were blocked in blocking buffer $(10 \mathrm{mmol} / \mathrm{L}$ Tris, $150 \mathrm{mmol} / \mathrm{L} \mathrm{NaCl}, 0.05 \%$ Tween-20, and 5\% bovine serum albumin; $\mathrm{pH}=7.3$ ) (Roche Diagnostics, S.L., Basel, Switzerland) at room temperature for $1 \mathrm{~h}$ under agitation. One of the blocked membranes was incubated with the antiAKR1B1 primary antibody (ref. HPA026425, Prestige Antibodies; Merck, Germany) diluted in blocking solution (1:2,000; v:v), and the other membrane with the same primary antibody (1:2000, v:v) and its blocking peptide (ref. APREST77862, Prestige Antibodies; Merck) 20 times more concentrated than the antibody. Both membranes were incubated at $4^{\circ} \mathrm{C}$ overnight. Next, membranes were washed three times with TBS-Tween $201 \times(10 \mathrm{mmol} / \mathrm{L}$ Tris, $150 \mathrm{mmol} / \mathrm{L} \mathrm{NaCl}$, and $0.05 \%$ Tween-20; $\mathrm{pH}=7.3$ ) for $5 \mathrm{~min}$ before incubation with an anti-rabbit, secondary antibody conjugated with HRP (ref. P0448; Sigma Aldrich) diluted in blocking solution (1:3,000; $\mathrm{v}: \mathrm{v})$. Membranes were washed 10 times and finally revealed using a chemiluminescent substrate (Immobilion ${ }^{\mathrm{TM}}$ Western Detection Reagents, Millipore); images were scanned with G:BOX Chemi XL 1.4. 


\section{Immunohistochemistry}

The sections of paraffin-embedded tissue samples (male reproductive organs and liver as a positive control) were immunohistochemically stained using an avidin-biotin complex protocol (Vector Laboratories, Burlingame, CA, United States). Briefly, sections were first deparaffinized two times using Histo-Clear II (Electron Microscopy Sciences, Hatfield, England) and progressively rehydrated through a decreasing ethanol series from 100 to $70 \%$ and distilled water. Next, and in order to allow antigen retrieval, sections were microwaved four times in $10 \mathrm{mM}$ Tris- $1 \mathrm{mM}$ EDTA buffer $(\mathrm{pH}=9.0)$ for $5 \mathrm{~min}$, with intermediate refiling with Tris-EDTA. Then, sections were washed with tap water and placed in racks. Samples were incubated with a blocking and permeabilizing solution composed of $3 \%$ bovine serum albumin (BSA) in $0.1 \%$ PBS-Tween at room temperature for $30 \mathrm{~min}$. Afterward, sections were incubated overnight at $4^{\circ} \mathrm{C}$ with the rabbit anti-AKR1B1 primary antibody diluted 1:100 (v:v) in PBS with $1 \%$ Triton X-100 containing 3\% BSA. As a negative control, the primary antibody was omitted. On the other hand, in order to prove antibody specificity, samples were incubated with the AKR1B1 primary antibody and its blocking peptide, which was 50 times in excess. The next day, sections were washed and subsequently incubated with a polyclonal goat anti-rabbit secondary antibody conjugated with biotin (EDM Millipore Corporation, Temecula, CA, United States) diluted 1:200 (v:v) in PBS containing 1\% Triton X-100 and $3 \% \mathrm{BSA}$ at room temperature for $30 \mathrm{~min}$. Sections were then washed and incubated with $3 \% \mathrm{H}_{2} \mathrm{O}_{2}$ in BSA-PBS for $20 \mathrm{~min}$ to block endogenous peroxidase activity. Next, all sections were incubated with the VECTASTAIN ABC reagent (Vector Laboratories, Burlingame, CA, United States) for $1 \mathrm{~h}$, and with $\mathrm{DAB}$ peroxidase substrate working solution (Vector Laboratories, Burlingame, CA, United States) for $10 \mathrm{~min}$. Slides were counterstained with Harris hematoxylin (Thermo Fisher Scientific, Waltham, MA, United States), dehydrated with an increasing ethanol series, and mounted with Eukitt ${ }^{\circledR}$ mounting medium (PanReac, Barcelona, Spain). Finally, slides were microscopically evaluated and photographed using Nikon Eclipse EP2000-S (Nikon).

\section{Enzyme-Linked Immunosorbent Assay}

Concentration of AKR1B1 in SP was quantified using a porcine-specific quantitative sandwich ELISA kit (MBS9316209; MyBioSource, San Diego, CA, United States) following the manufacturer's manual. Briefly, to obtain the standard curve, $50 \mu \mathrm{L}$ of AKR1B1 standards $(0.625,1.25,2.5,5,10$, and $20 \mathrm{ng} / \mathrm{mL}$ ) was added to the plate in duplicate. On the other hand, SP samples were thawed, diluted in PBS $1 \times(1: 75$; v:v) and added to the plate in duplicate. The content of all wells, except the blank ones, was mixed with $100 \mu \mathrm{L}$ of HRP-Conjugate Reagent, and the plate was subsequently incubated at $37^{\circ} \mathrm{C}$ for $60 \mathrm{~min}$. After washing all wells four times, $50 \mu \mathrm{L}$ of Chromogen A and $50 \mu \mathrm{L}$ of Chromogen B were added. After mixing gently, the plate, protected from light, was incubated at $37^{\circ} \mathrm{C}$ for $15 \mathrm{~min}$. Next, $50 \mu \mathrm{L}$ of the Stop solution was added to all wells and, after $5 \mathrm{~min}$, the plate was read at $450 \mathrm{~nm}$ using a microplate spectrophotometer (BioTek Epoch; BioTek, Winooski, Vermont, United States). The average of the duplicate reading for each standard was calculated and the average optical density from the blank was subtracted. Based on AKR1B1 standards, a linear regression curve interpolating AKR1B1 concentration from absorbance reading was calculated; the equation resulted to be: $[A K R 1 B 1]=A b s+0.038 / 0.0522$, $R^{2}=0.9772$.

This ELISA kit was highly specific for porcine AKR1B1, showing a sensitivity of $0.1 \mathrm{ng} / \mathrm{mL}$ and a detection range of $0.625-20 \mathrm{ng} / \mathrm{mL}$.

\section{Sperm Quality and Functionality Parameters' Assessments}

For evaluation of sperm quantity and functionality, seven parameters were assessed: (i) concentration, (ii) morphology, (iii) motility, (iv) viability, (v) intracellular $\mathrm{H}_{2} \mathrm{O}_{2}$ production by viable sperm, (vi) acrosome damage in viable sperm, and (vii) plasma membrane lipid disorder in viable sperm. Except for sperm concentration, which was only evaluated immediately after ejaculate collection $(0 \mathrm{~h})$, the other quality/functionality variables were determined at two time-points: after ejaculate collection $(0 \mathrm{~h})$ and after $72 \mathrm{~h}$ of liquid storage at $17^{\circ} \mathrm{C}(72 \mathrm{~h})$.

For sperm concentration assessment, a high-precision automated cell counter (NucleoCounter ${ }^{\circledR} \mathrm{NC}-100^{\mathrm{TM}}$, ChemoMetec, Allerod, Denmark) was used following manufacturer's recommendations. Sperm morphology was examined under a phase-contrast microscope at $1,000 \times$ magnification (Nikon Labophot, Nikon, Tokio, Japan) in semen samples diluted $(1: 1 ; \mathrm{v}: \mathrm{v})$ with $0.12 \%$ formaldehyde saline solution (Panreac). A total of 200 sperm cells were counted and classified as morphologically normal if they did not exhibit abnormal head, acrosome defects, proximal cytoplasmic droplets, distal cytoplasmic droplets, folded tails, or coiled tails. Sperm motility was assessed using a computer-assisted sperm analyzer (CASA, ISASV ${ }^{\circledR}$, Proiser R+D S.L., Paterna, Spain). For this analysis, $5 \mu \mathrm{L}$ of each semen sample $\left(30 \times 10^{6} \mathrm{sperm} / \mathrm{mL}\right.$ in Biosem+ $)$ was pipetted onto a pre-warmed $\left(38^{\circ} \mathrm{C}\right)$ Makler chamber (Sefi Medical Instruments, Haifa, Israel). A total of 10 different fields per sample accumulating $\geq 600$ sperm were acquired and examined. For further analysis, percentages of total motile sperm (sperm showing an average path velocity $\geq 20 \mu \mathrm{m} / \mathrm{s}$ ) and progressively motile sperm (exhibiting rapid and progressive movement with a straight-line velocity $\geq 40 \mu \mathrm{m} / \mathrm{s}$ ) were recorded.

Sperm viability, acrosome damage, intracellular $\mathrm{H}_{2} \mathrm{O}_{2}$ production, and membrane lipid disorder were assessed by flow cytometry (BD FACS Canto II; Becton Dickinson \& Company, Franklin Lakes, NJ, United States). For each semen sample and sperm parameter, three technical replicates with 10,000 Hoechst 33342 (H-42; Merck)-positive events were evaluated.

Sperm viability and acrosome damage were assessed using a triple-staining with Hoechst 33342 (H-42), propidium iodide (PI; Merck), and fluorescein-conjugated peanut agglutinin 
(PNA-FITC; Merck). Briefly, $100 \mu \mathrm{L}$ of each semen sample $\left(30 \times 10^{6}\right.$ sperm $/ \mathrm{mL}$ in Biosem +$)$ was incubated with $3 \mu \mathrm{L} \mathrm{H}-42(0.05 \mathrm{mg} / \mathrm{mL}$ in PBS), $2 \mu \mathrm{L}$ PI $(0.5 \mathrm{mg} / \mathrm{mL}$ in PBS), and $2 \mu \mathrm{L}$ PNA-FITC $(100 \mu \mathrm{g} / \mathrm{mL}$ in PBS) at $37^{\circ} \mathrm{C}$ (Sanyo MIR-153 incubator, Gemini BV, Apeldoorn, Netherlands) for $10 \mathrm{~min}$. Next, $400 \mu \mathrm{L}$ PBS was added to each sample. Percentages of viable spermatozoa (H-42+/PI-) with an intact (PNA-FITC-) and non-intact (PNA-FITC+) acrosome membrane were recorded.

To assess intracellular $\mathrm{H}_{2} \mathrm{O}_{2}$ production by viable sperm, a triple-staining with $\mathrm{H}-42, \mathrm{PI}$, and 5- and 6-chloromethyl$2^{\prime}, 7^{\prime}$-dichlorodihydrofluorescein diacetate acetyl ester (CM$\mathrm{H}_{2}$ DCFDA; Merck) was prepared. Briefly, $50 \mu \mathrm{L}$ of each semen sample $\left(30 \times 10^{6} \mathrm{sperm} / \mathrm{mL}\right.$ in Biosem +$)$ was incubated with $1.5 \mu \mathrm{L} \mathrm{H}-42(0.05 \mathrm{mg} / \mathrm{mL}$ in PBS $1 \times), 1 \mu \mathrm{L}$ PI $\left(0.5 \mathrm{mg} / \mathrm{mL}\right.$ in PBS), and $1 \mu \mathrm{L} \mathrm{CM}-\mathrm{H}_{2}$ DCFDA $(1 \mathrm{mM}$ in dymetilsulfoxide [DMSO]) in $950 \mu \mathrm{L}$ PBS at $37^{\circ} \mathrm{C}$ for $30 \mathrm{~min}$. An aliquot of each semen sample was incubated with all fluorochromes plus $1 \mu \mathrm{L}$ of tert-butyl hydroperoxide solution (70\% in distilled water) and was used as a positive control. The percentage of viable sperm $(\mathrm{H}-42+/ \mathrm{PI}-)$ that exhibited high intracellular $\mathrm{H}_{2} \mathrm{O}_{2}$ generation $\left(2^{\prime}, 7^{\prime}\right.$-di-chlorofluorescein $[\mathrm{DCF}]+)$ was recorded.

Finally, to evaluate the lipid disorder of plasma membrane in viable sperm, a triple-staining with $\mathrm{H}-42$, Yo-Pro-1 (Merck), and Merocyanine 540 (M-540; Merck) was carried out. Briefly, $50 \mu \mathrm{L}$ of each semen sample $\left(30 \times 10^{6}\right.$ sperm $/ \mathrm{mL}$ in Biosem+) was incubated with $2.5 \mu \mathrm{L} H-42$ and $10 \mu \mathrm{L}$ Yo-Pro-1 (2.5 $\mu \mathrm{M}$ in DMSO) in $950 \mu \mathrm{L}$ PBS at $37^{\circ} \mathrm{C}$ for $8 \mathrm{~min}$. After this period, $26 \mu \mathrm{L}$ of $\mathrm{M} 540(0.1 \mathrm{mM}$ in DMSO) was added to each sample and incubated at $37^{\circ} \mathrm{C}$ for $2 \mathrm{~min}$. The percentage of viable spermatozoa (H-42+/Yo-Pro-1-) exhibiting lipid membrane disorder (M$540+)$ was recorded.

\section{Statistical Analysis}

Data were analyzed using the statistical package IBM SPSS 25.0 for Windows (IBM corp., Armonk, NY, United States). First, normal distribution was tested with Shapiro-Wilk test and homogeneity of variances was checked with Levene test. Concentrations of AKR1B1 between the three SP portions (i.e., SRF-P1, SRF-P2, and PSRF) were compared through one-way analysis of variance (ANOVA) followed by post hoc Sidak test. Ejaculates were classified based on their AKR1B1 concentration into groups through a two-step cluster analysis using the log-likelihood distance and the Schwarz's Bayesian criterion. Following this, sperm quality and functionality variables (sperm motility and viability, intracellular $\mathrm{H}_{2} \mathrm{O}_{2}$ production by viable sperm, acrosome damage in viable sperm, and plasma membrane lipid disorder in viable sperm) were compared between the two groups of ejaculates (high SP-AKR1B1 and low AKR1B1) with a linear mixed model followed by post hoc Sidak test. In this model, between-subjects factor was the ejaculate group and within-subjects factor was the time of semen storage at $17^{\circ} \mathrm{C}$. When needed, data were linearly transformed with arcsine $\sqrt{ } \mathrm{x}$. The level of statistical significance was set at $P \leq 0.05$.

\section{RESULTS}

\section{Experiment 1: SP-AKR1B1 Concentration in Ejaculate Portions}

Concentrations of AKR1B1 in SP fractions/portions are shown in Figure 1. The SP from SRF-P1 from SRF-P1 exhibited the lowest $(P<0.05)$ AKR1B1 concentration $(458.2 \pm 116.33 \mathrm{ng} / \mathrm{mL})$ compared to SRF-P2 (1105.0 $\pm 229.80 \mathrm{ng} / \mathrm{mL})$ or PSRF $(1342.4 \pm 260.18 \mathrm{ng} / \mathrm{mL})$. Moreover, no differences $(P>0.05)$ in AKR1B1 concentrations were found between SRF-P2 and PSRF. Finally, no breed effect was observed in SP-AKR1B1 concentration, as Pietrain and Duroc boars showed similar concentrations $(522.2 \pm 66.85 \mathrm{ng} / \mathrm{mL}$ vs. $691.7 \pm 81.00 \mathrm{ng} / \mathrm{mL}$; $P>0.05)$.

\section{Experiment 2: Expression of AKR1B1 in Male Reproductive Organs}

The immunoblotting assay revealed the presence of AKR1B1 along the entire male reproductive tissues except for bulbourethral glands (Figure 2). Specifically, two specific bands were detected: (i) a $36 \mathrm{kDa}$ band was found in testis, epididymal caput and corpus, and seminal vesicles; and (ii) a $\sim 80 \mathrm{kDa}$ band was also identified in testis, cauda, caput and corpus of epididymis, seminal vesicles, and prostate. Both bands also appeared in the positive control (liver). The two bands were not seen when membranes were incubated with AKR1B1 blocking peptide, revealing that they were specific for AKR1B1. Therefore, bands of $\sim 40$ and $\sim 70 \mathrm{kDa}$ should be considered as unspecific for this antibody.

The AKR1B1 protein was immunohistochemically detected in the reproductive tissues analyzed (Figure 3 ). Two controls

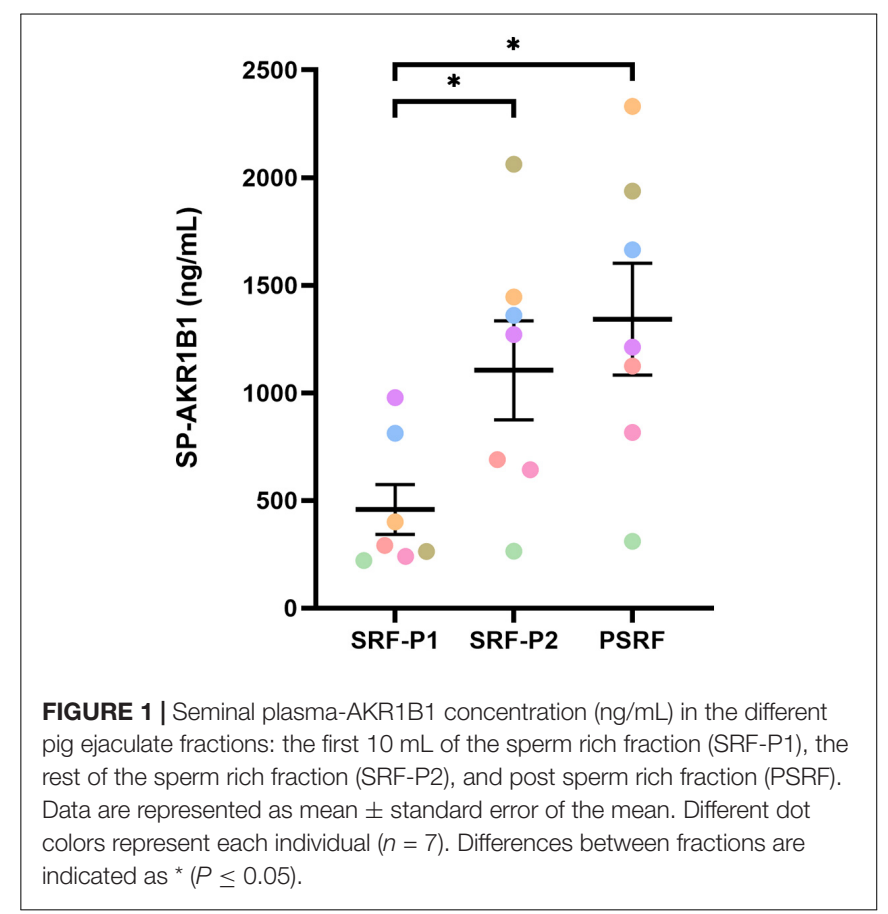



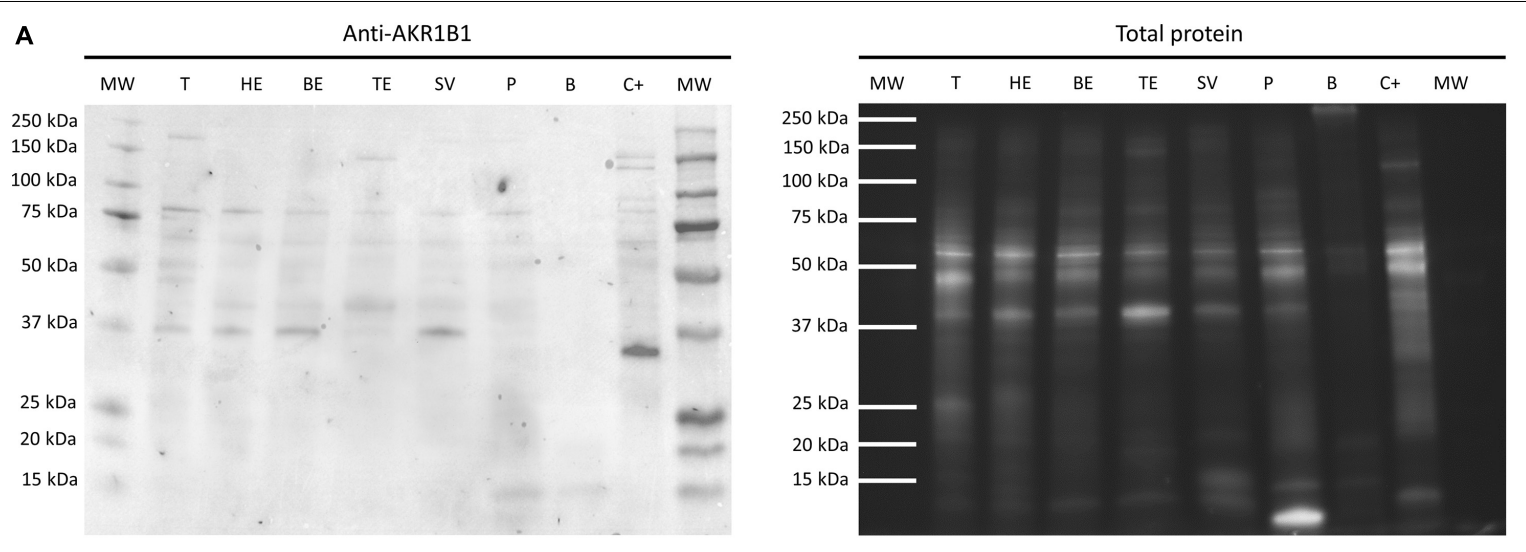

B

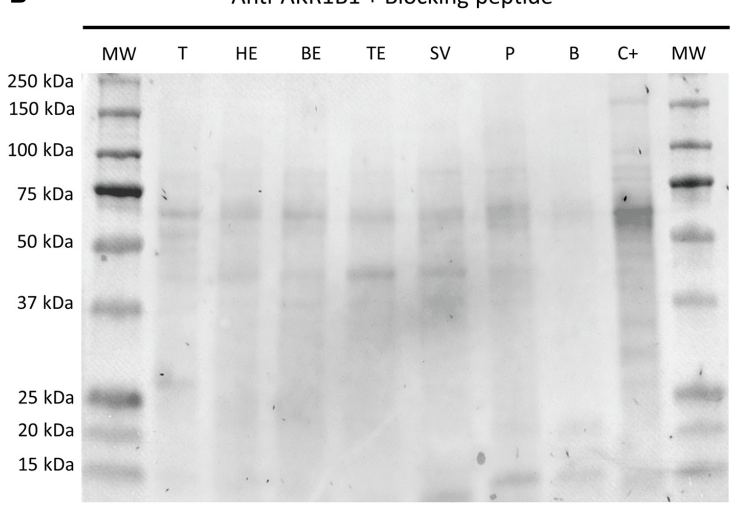

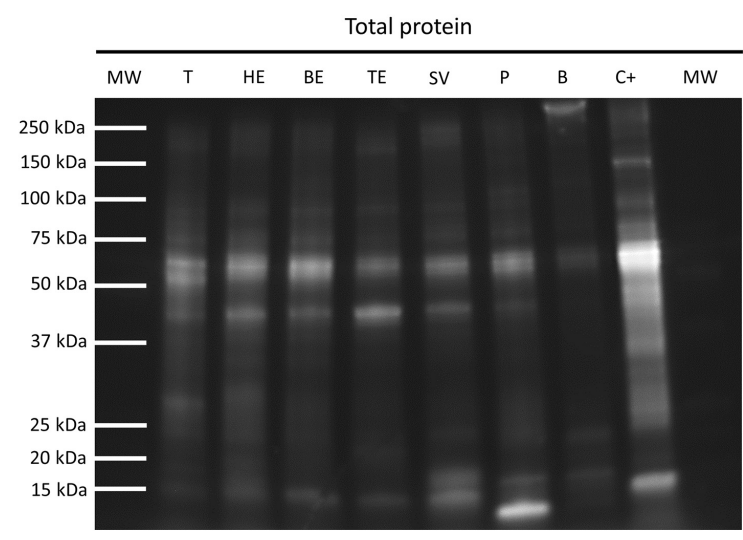

FIGURE 2 | Representative Western blot of (A) anti-AKR1B1 and (B) its corresponding blocking peptide, and their total protein controls in boar reproductive tissues. MW, molecular weight; T, testis; HE, caput epididymis; BE, corpus epididymis; TE, cauda epididymis; SV, seminal vesicles; P, prostate; B, bulbourethral glands; C+, liver.

were used: (i) the specificity of the primary antibody was confirmed in all tissues through incubation with the AKR1B1 primary antibody with blocking peptide and (ii) the specificity of the secondary antibody was proven with the omission of the primary antibody in all tissue samples. The presence of AKR1B1 was confirmed in all reproductive tissues except for bulbourethral glands, in which no staining was observed. In testis, AKR1B1 was observed in the interstitial tissue, specifically in the cytosol of Leydig cells, whereas no presence of the protein was detected in seminiferous tubules. Regarding epididymis, AKR1B1 was localized in basal and principal cells of the epithelia of all regions (caput, corpus, and cauda). In addition, both prostate and seminal vesicles showed cytoplasm immunostaining in glandular epithelial cells. Finally, AKR1B1 was undetectable in bulbourethral glands.

\section{Experiment 3: Relationship Between SP-AKR1B1 and Sperm Quality and Functionality Parameters}

In order to evaluate the relationship between SP-AKR1B1 and sperm quality and functionality parameters, 14 ejaculates were classified (hierarchical clustering; $P<0.001$ ) into two groups: with low SP-AKR1B1 (ranging from 376.4 to $756.3 \mathrm{ng} / \mathrm{mL}$, $n=7$ ) and high SP-AKR1B1 levels (ranging from 842.2 to $1211.25 \mathrm{ng} / \mathrm{mL}, n=7$; Figure 4). No differences $(P>0.05)$ in any of the different sperm quality and functionality parameters assessed (sperm concentration, normal sperm morphology, total and progressive motility, viable sperm, viable sperm with high intracellular $\mathrm{H}_{2} \mathrm{O}_{2}$, viable sperm with a damaged acrosome, and viable sperm with high membrane destabilization) were observed between high and low SP-AKR1B1 groups at any evaluation time-point ( 0 and $72 \mathrm{~h}$ of storage at $\left.17^{\circ} \mathrm{C}\right)$.

\section{DISCUSSION}

To the best of our knowledge, this is the first study characterizing the expression of AKR1B1 along the male reproductive system in livestock. Likewise, this report is also the first relating the concentration of AKR1B1 in SP with sperm quality and functionality parameters of liquidstored semen samples. Specifically, the results showed that: (i) monomeric and dimeric AKR1B1 forms were expressed in all male reproductive tissues, except bulbourethral glands; (ii) AKR1B1 was expressed in Sertoli cells, basal and principal 


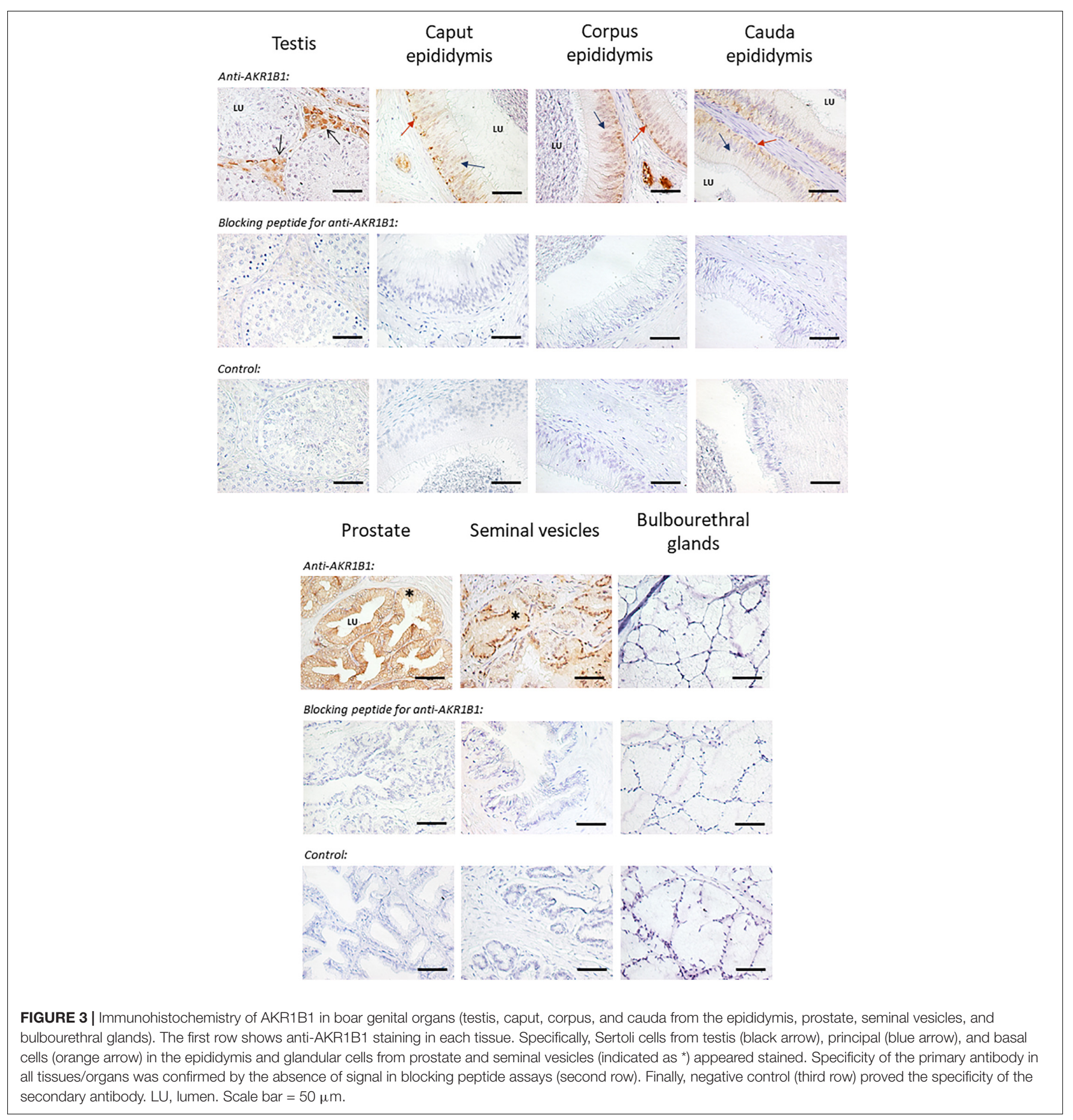

epididymal cells, and glandular cells from the prostate and seminal vesicles; (iii) seminal vesicles were likely to contribute the most to the final SP-AKR1B1 concentration of the pig ejaculate; and (iv) SP-AKR1B1 levels were not related to sperm quality and functionality parameters, nor was this enzyme involved in the sperm resilience to preservation at $17^{\circ} \mathrm{C}$ for $72 \mathrm{~h}$.

Characterization of SP components, including proteins or even metabolites, has been a source of sperm quality, functionality, and fertility biomarkers in several mammalian species (Milardi et al., 2013; Cazaux Velho et al., 2018; Moura et al., 2018; Pérez-Patiño et al., 2018). In this sense, as mentioned before, AKR1B1 has been reported to have multiple roles in the reproductive physiology of humans (Bresson et al., 2011), cattle (Frenette et al., 2004; Girouard et al., 2009), rodents (Kobayashi et al., 2002), and pigs (Steinhauser et al., 2016; Pérez-Patiño et al., 2018). However, no information regarding its synthesis along the male reproductive tract exists in any mammalian species. 

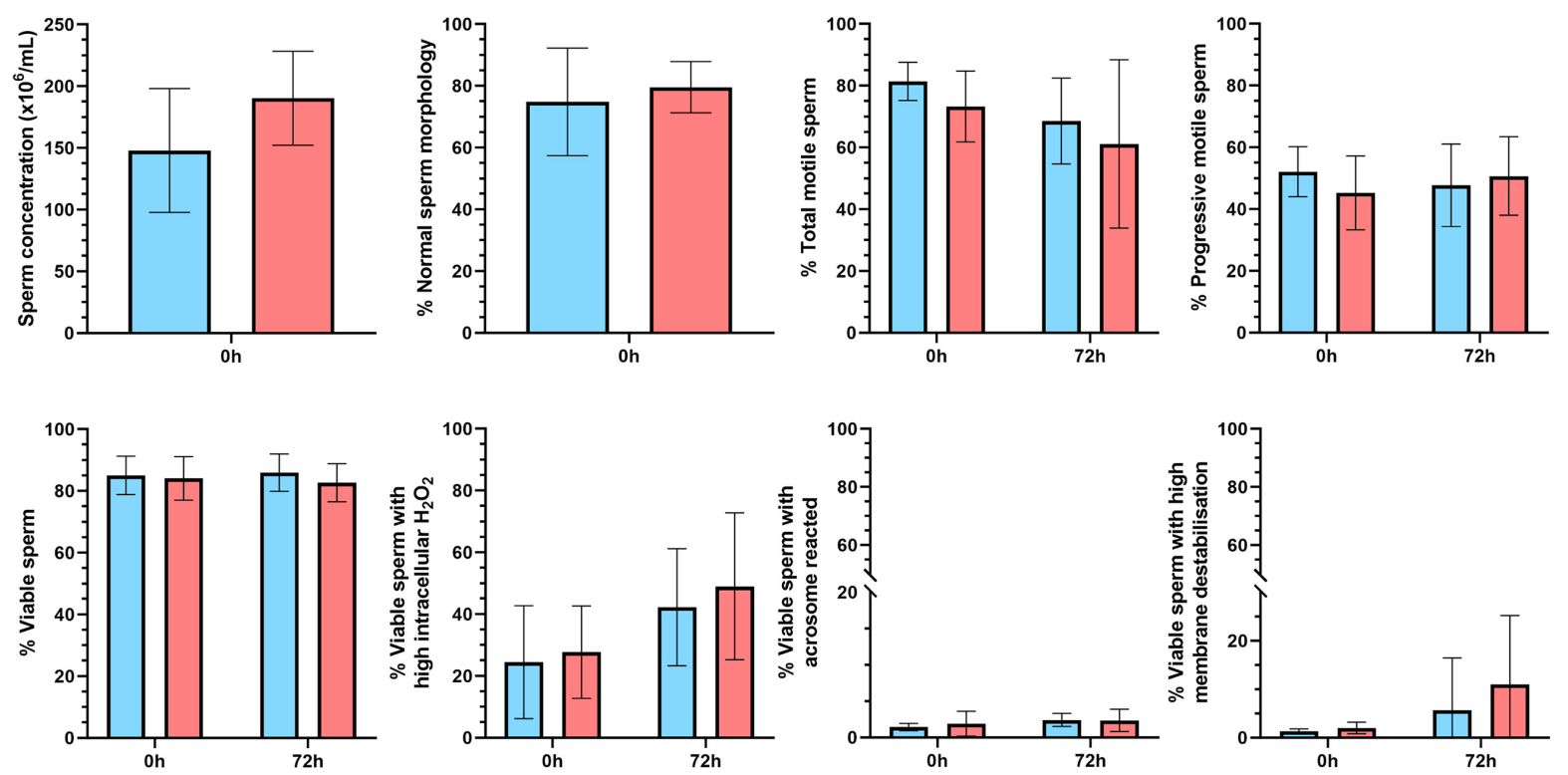

FIGURE 4 | Sperm quality and functionality parameters upon semen collection $(0 \mathrm{~h})$ and after $72 \mathrm{~h}$ of liquid storage at $17^{\circ} \mathrm{C}$ in two groups ejaculates clustered on the basis of AKR1B1 concentration in seminal plasma (SP) samples. Fourteen ejaculates were classified into two groups: with low SP-AKR1B1 levels (ranging from 376.4 to $756.3 \mathrm{ng} / \mathrm{mL}, n=7$; blue bars) and with high SP-AKR1B1 levels (ranging from 842.2 to $1211.25 \mathrm{ng} / \mathrm{mL}, n=7 ;$ red bars). Data are represented as mean \pm standard error of the mean.

The immunoblotting and immunohistochemistry results showed that AKR1B1 was expressed in testis, epididymis, and all accessory sex glands, except the bulbourethral ones. These results are in agreement with observations in male rats, in which the activity of aldose reductase was observed along all the male reproductive tract, except in bulbourethral glands that were not analyzed (Kobayashi et al., 2002; Iuchi et al., 2004). Moreover, other studies conducted in cattle and pigs demonstrated the presence of AKR1B1 in seminal vesicles (Samuels et al., 1962; Westfalewicz et al., 2017). This protein has been reported to interact with epididymal sperm during maturation (Frenette et al., 2003, 2006; Katoh et al., 2014), which would advise a role of AKR1B1 in sperm physiology. In this context, the presence of AKR1B1 has been proposed to contribute to the acquisition of sperm motility and fertilizing ability in pigs (Katoh et al., 2014), as well as to support bovine sperm survival during epididymal transit and storage (Frenette et al., 2003). In addition, our immunoblotting assay showed the presence of one or two specific bands ( 36 and $\sim 80 \mathrm{kDa}$ ) in most male reproductive tissues. While dimerization of $\mathrm{AKR} 1 \mathrm{~B} 1$ has been previously reported in ovine thymus (Yang et al., 2019) and bovine peripheral blood mononuclear cells (Yang et al., 2016), there are no previous studies of such a dimerization in SP samples from any mammalian species. Indeed, as monomeric and dimeric protein forms are known to have different cellular functions, further studies should address whether these forms could explain the different roles of SP-AKR1B1 in reproductive physiology.

Besides the presence of AKR1B1 along the male reproductive tract, our study found that this protein was only present in specific cell types, rather than in the lumen of the different organs. Specifically, in testis, only Leydig cells were stained with the anti-AKR1B1 antibody. Since these cells are implicated in hormonal secretion and spermatogenesis regulation (Zhou et al., 2019), one could hypothesize that AKR1B1 is involved in these processes. On the other hand, AKR1B1 was also found in both basal and principal cells along the entire epididymis and glandular cells from the prostate and seminal vesicles. Considering that all of these cell types are involved in protein secretion (Leung et al., 2004; Breton et al., 2019), the presence of AKR1B1 in SP can be assumed to be originated from the collective synthesis and secretion of the aforementioned organs. These findings are in agreement with a previous study conducted in bovine, in which aldose reductase was also reported to be present in the same epididymal and testicular cells lines (Frenette et al., 2003). However, this is the first report in a mammalian species describing that vesicle glands are the main synthesis site. Nevertheless, to the best of our knowledge, neither the exact contribution of the different male accessory glands to AKR1B1 levels in SP, nor its potential role on ejaculated sperm has been uncovered.

ELISA assay of the different ejaculate portions confirmed immunohistochemical and immunoblotting results, indicating that whereas AKR1B1 was present in the SP from all ejaculate portions, a higher concentration of this protein was found in the SP from PSRF. As aforementioned, SP from each ejaculate portion has a different origin: SP from SRF-P1 is mainly secreted by the epididymis, SP from SRF-P2 originates from the epididymis and prostate, and SP from PSRF is mainly produced by seminal vesicles (Einarsson, 1971; Rodríguez-Martínez et al., 2009; Saravia et al., 2009; Rodríguez-Martínez et al., 2011). Considering these results, one could hypothesize that seminal vesicles are the principal contributor for SP-AKR1B1 secretion to 
the entire ejaculate. Similar results have been reported in bovine, where this enzyme is one of the most abundant proteins of the seminal vesicle fluid (Westfalewicz et al., 2017).

The present study also evaluated the relationship between SP-AKR1B1 concentration and sperm quality and functionality after both 0 and $72 \mathrm{~h}$ of liquid storage at $17^{\circ} \mathrm{C}$. No relationship between SP-AKR1B1 concentration and any of the evaluated parameters, which included sperm concentration, normal sperm morphology, total and progressive motility, sperm viability, and percentages of viable sperm with high intracellular ROS, viable sperm with a damaged acrosome, and viable sperm with high membrane destabilization, was observed. To the best of our knowledge, there is scarce information regarding the role of AKR1B1 in sperm physiology. While AKR1B1 has been reported to be overexpressed in men with high seminal lipid peroxidation levels (Intasqui et al., 2015) and to be involved in porcine sperm capacitation (Katoh et al., 2014), none of these parameters were evaluated in the present study. Thus, taking into account the lack of influence of SP-AKR1B1 on sperm quality and functionality found in our study, together with the fact that the highest SP-AKR1B1 concentration was not found in the SRF (which contains most of the ejaculated sperm; Einarsson, 1971; Rodríguez-Martínez et al., 2009; Saravia et al., 2009; RodríguezMartínez et al., 2011), it is reasonable to surmise that SP-AKR1B1 does not play a major role on the sperm quality and functionality parameters assessed. However, this protein could play a crucial role on sperm lipid peroxidation or during capacitation. Further studies are required to evaluate this potential relationship.

Besides its relevance during epididymal maturation (Frenette et al., 2003; Katoh et al., 2014), SP-AKR1B1 could have a potential influence on the female reproductive tract, as it is expressed in the endometrium in humans (Chapdelaine et al., 2006; Bresson et al., 2011) and pigs (Seo et al., 2014; Steinhauser et al., 2016). In the uterus, the luminal AKR1B1 has been found to be involved in the polyol pathway during the conceptus peri-implantation period and, in porcine, its expression is downregulated as conceptus attaches to the endometrium (Steinhauser et al., 2016). On the other hand, uterine AKR1B1 is involved in progesterone synthesis in humans (Bresson et al., 2011) and pigs (Seo et al., 2014), thus contributing to prepare the endometrium for conceptus implantation as well as modulating the maternal immune system (Czyzyk et al., 2017). Our results, together with the fact that SP-AKR1B1 is linked with high in vivo pregnancy outcomes (Pérez-Patiño et al., 2018), suggest that SP-AKR1B1 could act jointly with the endometrial AKR1B1 to prepare the uterine environment for conceptus implantation. Another possibility could be that this protein has a direct impact on conceptus. In this sense, SP has been reported to exert a positive effect on pregnancy outcomes, specifically improving implantation and pregnancy rates in humans (Crawford et al., 2015; Saccone et al., 2019) and even modifying embryo gene expression in pigs (Martinez et al., 2020). Thus, it cannot be discarded the influence of SP-AKR1B1 on the improvement of embryo survival and even implantation, through the modulation of the uterine environment. In this regard, all these functions could be driven by both the soluble form of the protein in SP or by that contained in extracellular vesicles (EVs). SP EVs regulate sperm function through its integration to sperm membrane (Leahy et al., 2020) and their action on the female immune system (Zhang et al., 2020). Interestingly, bovine AKR1B1 has been reported to be associated to epididymal EVs (Frenette et al., 2006) and, in humans, seminal EVs have been found to contain aldose reductase (Zhang et al., 2020). In pigs, however, whether this protein is also in the cargo of SP EVs and participates in fertilization or embryo development remains to be explored.

AKR1B1 has been extensively demonstrated to play a role in female and male reproductive physiology. In pigs, SP-AKR1B1 has been reported to exert a positive impact on in vivo fertility outcomes. This study demonstrated that all male genital organs (except bulbourethral glands) are able to express AKR1B1. We also found that the concentration of AKR1B1 was higher in the post-SRF, suggesting that seminal vesicles could be the main contributor of this SP protein to the final ejaculate. Our results also indicated that SP-AKR1B1 is not associated to the quality and functionality parameters of sperm. These findings, together with the fact that this protein has been shown to be positively related to in vivo fertility (Pérez-Patiño et al., 2018), suggest that it could play an active role in the female reproductive tract, promoting sperm fecundity or even embryo development. Thus, further studies to determine the exact mechanism through which SP-AKR1B1 has a positive influence on in vivo fertility outcomes should be conducted.

\section{DATA AVAILABILITY STATEMENT}

The raw data supporting the conclusions of this article will be made available by the authors, without undue reservation.

\section{AUTHOR CONTRIBUTIONS}

YM-O, MY, and IB: conceptualization. YM-O, EV-V, and ML: methodology. YM-O, JR-M, MY, and IB: formal analysis and investigation. YM-O and EV-V: writing-original draft preparation. JR-M, JR, MY, and IB: writing-review and editing. JR and MY: funding acquisition. IB and MY: supervision. All authors read and agreed to the published version of the manuscript.

\section{FUNDING}

This study was funded by the Ministry of Science and Innovation, Spain (Grants: RYC-2014-15581 and AGL201788329-R), European Union's Horizon 2020 Research and innovation Scheme (H2020-MSCA-IF-2019-891382), the Seneca Foundation Murcia, Spain (19892/GERM-15), and the Regional Government of Catalonia (Grants: 2017-SGR-1229 and 2020-FIB-00412).

\section{ACKNOWLEDGMENTS}

The authors would like to thank AIM Iberica (Topigs Norsvin Iberica, Spain) for boar ejaculates. 


\section{REFERENCES}

Barranco, I., Padilla, L., Tvarijonaviciute, A., Parrilla, I., Martínez, E. A., RodriguezMartinez, H., et al. (2019). Levels of activity of superoxide dismutase in seminal plasma do not predict fertility of pig AI-semen doses. Theriogenology 140, 18-24. doi: 10.1016/j.theriogenology.2019.08.010

Barranco, I., Perez-Patiño, C., Tvarijonaviciute, A., Parrilla, I., Vicente-Carrillo, A., Alvarez-Rodriguez, M., et al. (2017). Active paraoxonase 1 is synthesised throughout the internal boar genital organs. Reproduction 154, 237-243. doi: 10.1530/REP-17-0300

Barranco, I., Tvarijonaviciute, A., Perez-Patinõ, C., Parrilla, I., Ceron, J. J., Martinez, E. A., et al. (2015). High total antioxidant capacity of the porcine seminal plasma (SP-TAC) relates to sperm survival and fertility. Sci. Rep. 5:18538. doi: $10.1038 /$ srep 18538

Barranco, S., Tvarijonaviciute, A., Perez-Patiho, C., Vicente-Carrillo, A., Parrilla, N., Ceron, J. J., et al. (2016). Glutathione peroxidase 5 is expressed by the entire pig male genital tract and once in the seminal plasma contributes to sperm survival and in vivo fertility. PLoS One 11:e0162958. doi: 10.1371/journal.pone. 0162958

Bohren, K. M., Bullock, B., Wermuth, B., and Gabbay, K. H. (1989). The aldo-keto reductase superfamily. cDNAs and deduced amino acid sequences of human aldehyde and aldose reductases. J. Biol. Chem. 264, 9547-9551. doi: 10.1016/ B978-0-12-801238-3.64092-8

Bresson, E., Boucher-Kovalik, S., Chapdelaine, P., Madore, E., Harvey, N., Laberge, P. Y., et al. (2011). The human aldose reductase AKR1B1 qualifies as the primary prostaglandin F synthase in the endometrium. J. Clin. Endocrinol. Metab. 96, 210-219. doi: 10.1210/jc.2010-1589

Breton, S., Nair, A. V., and Battistone, M. A. (2019). Epithelial dynamics in the epididymis: role in the maturation, protection, and storage of spermatozoa. Andrology 7, 631-643. doi: 10.1111/andr.12632

Cazaux Velho, A. L., Menezes, E., Dinh, T., Kaya, A., Topper, E., Moura, A. A., et al. (2018). Metabolomic markers of fertility in bull seminal plasma. PLoS One 13:e0195279. doi: 10.1371/journal.pone.0195279

Chapdelaine, P., Kang, J., Boucher-Kovalik, S., Caron, N., Tremblay, J. P., and Fortier, M. A. (2006). Decidualization and maintenance of a functional prostaglandin system in human endometrial cell lines following transformation with SV40 large T antigen. Mol. Hum. Reprod. 12, 309-319. doi: 10.1093/ molehr/gal034

Chiba, L. (2009). "Pig nutrition and feeding," in Animal Nutrition Handbook, ed. L. Chiba (Auburn: Auburn University), 285-315.

Crawford, G., Ray, A., Gudi, A., Shah, A., and Homburg, R. (2015). The role of seminal plasma for improved outcomes during in vitro fertilization treatment: review of the literature and meta-analysis. Hum. Reprod. Update 21, 275-284. doi: 10.1093/humupd/dmu052

Czyzyk, A., Podfigurna, A., Genazzani, A. R., and Meczekalski, B. (2017). The role of progesterone therapy in early pregnancy: from physiological role to therapeutic utility. Gynecol. Endocrinol. 33, 421-424. doi: 10.1080/09513590. 2017.1291615

Einarsson, S. (1971). Studies on the composition of epididymal content and semen in the boar. Acta Vet. Scand. Suppl. 36, 1-80.

Frenette, G., Girouard, J., and Sullivan, R. (2006). Comparison between epididymosomes collected in the intraluminal compartment of the bovine caput and cauda epididymidis. Biol. Reprod. 75, 885-890. doi: 10.1095/biolreprod.106. 054692

Frenette, G., Lessard, C., Madore, E., Fortier, M. A., and Sullivan, R. (2003). Aldose reductase and macrophage migration inhibitory factor are associated with epididymosomes and spermatozoa in the bovine epididymis. Biol. Reprod. 69, 1586-1592. doi: 10.1095/biolreprod.103.019216

Frenette, G., Lessard, C., and Sullivan, R. (2004). Polyol pathway along the bovine epididymis. Mol. Reprod. Dev. 69, 448-456. doi: 10.1002/mrd.20170

Garner, D. L., and Hafez, E. S. E. (2000). "Spermatozoa and seminal plasma," in Reproduction in Farm Animals, eds B. Hafez and E. S. E. Hafez (Philadelphia, PA: Lippincott Williams \& Wilkins), 96-109. doi: 10.1002/9781119265306.ch7

Girouard, J., Frenette, G., and Sullivan, R. (2009). Compartmentalization of proteins in epididymosomes coordinates the association of epididymal proteins with the different functional structures of bovine spermatozoa. Biol. Reprod. 80, 965-972. doi: 10.1095/biolreprod.108.073551
Hyndman, D., Bauman, D. R., Heredia, V. V., and Penning, T. M. (2003). The aldo-keto reductase superfamily homepage. Chem. Biol. Interact. 14, 621-631. doi: 10.1016/S0009-2797(02)00193-X

Intasqui, P., Antoniassi, M. P., Camargo, M., Nichi, M., Carvalho, V. M., Cardozo, K. H. M., et al. (2015). Differences in the seminal plasma proteome are associated with oxidative stress levels in men with normal semen parameters. Fertil. Steril. 104, 292-301. doi: 10.1016/j.fertnstert.2015.04.037

Iuchi, Y., Kaneko, T., Matsuki, S., Ishii, T., Ikeda, Y., Uchida, K., et al. (2004). Carbonyl stress and detoxification ability in the male genital tract and testis of rats. Histochem. Cell Biol. 121, 123-130. doi: 10.1007/s00418-003-0607-3

Jagoe, W. N., Howe, K., O'Brien, S. C., and Carroll, J. (2013). Identification of a role for a mouse sperm surface aldo-keto reductase (AKR1B7) and its human analogue in the detoxification of the reactive aldehyde, acrolein. Andrologia 45, 326-331. doi: 10.1111/and.12018

Katoh, Y., Takebayashi, K., Kikuchi, A., Iki, A., Kikuchi, K., Tamba, M., et al. (2014). Porcine sperm capacitation involves tyrosine phosphorylation and activation of aldose reductase. Reproduction 148, 389-401. doi: 10.1530/REP-14-0199

Kennedy, T. G., Gillio-Meina, C., and Phang, S. H. (2007). Prostaglandins and the initiation of blastocyst implantation and decidualization. Reproduction 134, 635-643. doi: 10.1530/REP-07-0328

Kobayashi, T., Kaneko, T., Iuchi, Y., Matsuki, S., Takahashi, M., Sasagawa, I., et al. (2002). Localization and physiological implication of aldose reductase and sorbitol dehydrogenase in reproductive tracts and spermatozoa of male rats. J. Androl. 23, 674-684. doi: 10.1002/j.1939-4640.2002.tb02310.x

Kumaresan, A., Kadirvel, G., Bujarbaruah, K. M., Bardoloi, R. K., Das, A., Kumar, S., et al. (2009). Preservation of boar semen at 18 degrees C induces lipid peroxidation and apoptosis like changes in spermatozoa. Anim. Reprod. Sci. 110, 162-171. doi: 10.1016/j.anireprosci.2008.01.006

Leahy, T., Rickard, J. P., Bernecic, N. C., Druart, X., and De Graaf, S. P. (2019). Ram seminal plasma and its functional proteomic assessment. Reproduction 157, R243-R256. doi: 10.1530/REP-18-0627

Leahy, T., Rickard, J. P., Pini, T., Gadella, B. M., and Graaf, S. P. (2020). Quantitative proteomic analysis of seminal plasma, sperm membrane proteins, and seminal extracellular vesicles suggests vesicular mechanisms aid in the removal and addition of proteins to the ram sperm membrane. Proteomics 20:1900289. doi: 10.1002/pmic.201900289

Leung, G. P. H., Cheung, K. H., Leung, C. T., Tsang, M. W., and Wong, P. Y. D. (2004). Regulation of epididymal principal cell functions by basal cells: role of transient receptor potential (Trp) proteins and cyclooxygenase-1 (COX-1). Mol. Cell. Endocrinol. 216, 5-13. doi: 10.1016/j.mce.2003.10.077

Li, J., Barranco, I., Tvarijonaviciute, A., Molina, M. F., Martinez, E. A., RodriguezMartinez, H., et al. (2018). Seminal plasma antioxidants are directly involved in boar sperm cryotolerance. Theriogenology 107, 27-35. doi: 10.1016/j. theriogenology.2017.10.035

Locatello, L., Poli, F., and Rasotto, M. B. (2013). Tactic-specific differences in seminal fluid influence sperm performance. Proc. R. Soc. B Biol. Sci. 280:20122891. doi: 10.1098/rspb.2012.2891

Martinez, C. A., Cambra, J. M., Gil, M. A., Parrilla, I., Alvarez-Rodriguez, M., Rodriguez-Martinez, H., et al. (2020). Seminal plasma induces overexpression of genes associated with embryo development and implantation in day- 6 porcine blastocysts. Int. J. Mol. Sci. 21, 1-14. doi: 10.3390/ijms21103662

Mateo-Otero, Y., Fernández-López, P., Gil-Caballero, S., Fernandez-Fuertes, B., Bonet, S., Barranco, I., et al. (2020). 1H nuclear magnetic resonance of pig seminal plasma reveals intra-ejaculate variation in metabolites. Biomolecules 10, 1-16. doi: 10.3390/biom 10060906

Milardi, D., Grande, G., Vincenzoni, F., Castagnola, M., and Marana, R. (2013). Proteomics of human seminal plasma: identification of biomarker candidates for fertility and infertility and the evolution of technology. Mol. Reprod. Dev. 80, 350-357. doi: 10.1002/mrd.22178

Moura, A. A., Memili, E., Portela, A. M. R., Viana, A. G., Velho, A. L. C., Bezerra, M. J. B., et al. (2018). Seminal plasma proteins and metabolites: effects on sperm function and potential as fertility markers. Anim. Reprod. 15, 691-702. doi: 10.21451/1984-3143-AR2018-0029

Muhammad Aslam, M. K., Kumaresan, A., Sharma, V. K., Tajmul, M., Chhillar, S., Chakravarty, A. K., et al. (2014). Identification of putative fertility markers in seminal plasma of crossbred bulls through differential proteomics. Theriogenology 82, 1254-1262.e1. doi: 10.1016/j.theriogenology.2014.08.007 
Novak, S., Smith, T. A., Paradis, F., Burwash, L., Dyck, M. K., Foxcroft, G. R., et al. (2010). Biomarkers of in vivo fertility in sperm and seminal plasma of fertile stallions. Theriogenology 74, 956-967. doi: 10.1016/j.theriogenology.2010.04. 025

O'Leary, S., Jasper, M. J., Warnes, G. M., Armstrong, D. T., and Robertson, S. A. (2004). Seminal plasma regulates endometrial cytokine expression, leukocyte recruitment and embryo development in the pig. Reproduction 128, 237-247. doi: 10.1530/rep.1.00160

Padilla, L., Barranco, I., Parrilla, I., Lucas, X., Rodriguez-Martinez, H., and Roca, J. (2020). Measurable cytokine concentrations in pig seminal plasma are modified by semen handling and storage. Biology (Basel) 9:276. doi: 10.3390/ biology 9090276

Perez-Patiño, C., Barranco, I., Parrilla, I., Valero, M. L., Martinez, E. A., RodriguezMartinez, H., et al. (2016). Characterization of the porcine seminal plasma proteome comparing ejaculate portions. J. Proteomics 142, 15-23. doi: 10.1016/ j.jprot.2016.04.026

Pérez-Patiño, C., Parrilla, I., Barranco, I., Vergara-Barberán, M., Simó-Alfonso, E. F., Herrero-Martínez, J. M., et al. (2018). New in-depth analytical approach of the porcine seminal plasma proteome reveals potential fertility biomarkers. J. Proteome Res. 17, 1065-1076. doi: 10.1021/acs.jproteome.7b00728

Robertson, S. A. (2007). Seminal fluid signaling in the female reproductive tract: lessons from rodents and pigs. J. Anim. Sci. 85, 36-44. doi: 10.2527/jas.2006578

Rodríguez-Martínez, H., Kvist, U., Ernerudh, J., Sanz, L., and Calvete, J. J. (2011). Seminal plasma proteins: what role do they play? Am. J. Reprod. Immunol. 66, 11-22. doi: 10.1111/j.1600-0897.2011.01033.x

Rodríguez-Martínez, H., Kvist, U., Saravia, F., Wallgren, M., Johannisson, A., Sanz, L., et al. (2009). The physiological roles of the boar ejaculate. Soc. Reprod. Fertil. Suppl. 66, 1-21.

Rodríguez-Martínez, H., Saravia, F., Wallgren, M., Tienthai, P., Johannisson, A., Vázquez, J. M., et al. (2005). Boar spermatozoa in the oviduct. Theriogenology 63, 514-535. doi: 10.1016/j.theriogenology.2004.09.028

Saccone, G., Di Spiezio Sardo, A., Ciardulli, A., Caissutti, C., Spinelli, M., Surbek, D., et al. (2019). Effectiveness of seminal plasma in in vitro fertilisation treatment: a systematic review and meta-analysis. BJOG 126, 220-225. doi: 10.1111/1471-0528.15004

Samuels, L. T., Harding, B. W., and Mann, T. (1962). Aldose reductase and ketose reductase in male accessory organs of reproduction. Distribution and relation to seminal fructose. Biochem. J. 84, 39-45. doi: 10.1042/bj08 40039

Saravia, F., Wallgren, M., Johannisson, A., Calvete, J. J., Sanz, L., Peña, F. J., et al. (2009). Exposure to the seminal plasma of different portions of the boar ejaculate modulates the survival of spermatozoa cryopreserved in MiniFlatPacks. Theriogenology 71, 662-675. doi: 10.1016/j.theriogenology.2008. 09.037
Schjenken, J. E., and Robertson, S. A. (2014). Seminal fluid and immune adaptation for pregnancy - comparative biology in mammalian species. Reprod. Domest. Anim. 49, 27-36. doi: 10.1111/rda.12383

Seo, H., Choi, Y., Shim, J., Yoo, I., and Ka, H. (2014). Comprehensive analysis of prostaglandin metabolic enzyme expression during pregnancy and the characterization of AKR1B1 as a prostaglandin F synthase at the maternalconceptus interface in pigs. Biol. Reprod. 90, 1-13. doi: 10.1095/biolreprod.113. 114926

Steinhauser, C. B., Landers, M., Myatt, L., Burghardt, R. C., Vallet, J. L., Bazer, F. W., et al. (2016). Fructose synthesis and transport at the uterine-placental interface of pigs: cell-specific localization of SLC2A5, SLC2A8, and components of the polyol pathway. Biol. Reprod. 95:108. doi: 10.1095/biolreprod.116.142174

Waberski, D., Riesenbeck, A., Schulze, M., Weitze, K. F., and Johnson, L. (2019). Application of preserved boar semen for artificial insemination: past, present and future challenges. Theriogenology 137, 2-7. doi: 10.1016/j.theriogenology. 2019.05.030

Westfalewicz, B., Dietrich, M. A., Mostek, A., Partyka, A., Bielas, W., Nińañski, W., et al. (2017). Analysis of bull (Bos taurus) seminal vesicle fluid proteome in relation to seminal plasma proteome. J. Dairy Sci. 100, 2282-2298. doi: 10.3168/jds.2016-11866

Yang, L., Lv, W., Liu, Y., Chen, K., Xue, J., Wang, Q., et al. (2019). Effect of early pregnancy on the expression of prostaglandin synthases in the ovine thymus. Theriogenology 136, 166-171. doi: 10.1016/j.theriogenology.2019.06.040

Yang, L., Yao, X., Li, S., Chen, K., Wang, Y., Chen, L., et al. (2016). Expression of genes associated with luteolysis in peripheral blood mononuclear cells during early pregnancy in cattle. Mol. Reprod. Dev. 83, 509-515. doi: 10.1002/mrd. 22647

Zhang, X., Vos, H. R., Tao, W., and Stoorvogel, W. (2020). Proteomic profiling of two distinct populations of extracellular vesicles isolated from human seminal plasma. Int. J. Mol. Sci. 21, 1-19. doi: 10.3390/ijms21217957

Zhou, R., Wu, J., Liu, B., Jiang, Y., Chen, W., Li, J., et al. (2019). The roles and mechanisms of Leydig cells and myoid cells in regulating spermatogenesis. Cell. Mol. Life Sci. 76, 2681-2695. doi: 10.1007/s00018-019-03101-9

Conflict of Interest: The authors declare that the research was conducted in the absence of any commercial or financial relationships that could be construed as a potential conflict of interest.

Copyright (C) 2021 Mateo-Otero, Viñolas-Vergés, Llavanera, Ribas-Maynou, Roca, Yeste and Barranco. This is an open-access article distributed under the terms of the Creative Commons Attribution License (CC BY). The use, distribution or reproduction in other forums is permitted, provided the original author(s) and the copyright owner(s) are credited and that the original publication in this journal is cited, in accordance with accepted academic practice. No use, distribution or reproduction is permitted which does not comply with these terms. 